\title{
Ortaokul Öğrencilerinin Araştırma-Sorgulamaya Yönelik Tutumları
}

\author{
DOI: $10.26466 /$ opus.892503
}

\author{
$*$ \\ Mehmet Özcan* \\ *Doç. Dr., Nevşehir Hacı Bektaşı Veli Üniversitesi, Nevşehir/Türkiye \\ E-Posta: $\underline{\text { mehmetozcan79@gmail.com }}$ \\ ORCID: $\underline{0000-0002-5451-0773}$
}

\section{Öz}

Bu araştırma ortaokul öğrencilerinin araştırma-sorgulama tutum düzeylerini ortaya çıkarmayı amaçlamaktadır. Bu amaca uygun olarak ortaokul öğrencilerine yönelik 'Araştırma-Sorgulamaya Yönelik Tutum Ölçeği' ile cinsiyet ve sınıf düzeyi değişkenleri kullanılmıştır. Araştırmaya ortaokul kademesinde eğitim gören tüm sınıf düzeylerinden toplam 564 öğrenci katılmıştır. Araştırma verileri SPSS programı ile analiz edilmiştir. Araştırmada elde edilen veriler $t$ testi ve Tek-Yön ANOVA testi ile analiz edilmiştir. Ortaokul öğrencilerinin araştırma-sorgulama tutum düzeyi ortalama puanı 5 üzerinden $\bar{X}=$ 2.03 bulunmuştur. Ayrıca ölçeğin merak duyma alt-boyutu ortalama puanı $\bar{X}=1.81$, Kaçınma altboyutu ortalama puanı $\bar{X}=2.11$ ve değer verme alt-boyutu ortalama puanı $\bar{X}=2.16$ olarak bulunmuştur. Ölçeğin geneli incelendiğginde KMO değeri .85, Bartlett's testi sonucu 1401.875 ve Cronbach alpha katsayı değeri 80 olarak bulunmuştur. Ölçeğin merak duyma alt-boyutunda Cronbach alpha katsayı değeri .52, kaçınma alt-boyutunda Cronbach alpha katsayı değeri .75 ve değer verme alt-boyutunda Cronbach alpha katsayı değeri 66 olarak bulunmuştur. Araştırma bulgularına göre ortaokul öğrencilerinin araştırma-sorgulamaya yönelik tutumları cinsiyete göre anlamlı farklılı göstermektedir $(p<.05)$. Ortaokul öğrencilerinin araştırma-sorgulamaya yönelik tutumları sinıf düzeyine göre anlaml farklilık göstermektedir $(p<.05)$ ve bu farklılık 5. simıfile 6. Sinıf, 5.sinıf ile 7. sinffve 5. sinıfile 8 sinıflar arasindadir.

Anahtar Kelimeler: Araştırma, Sorgulama, Tutum, Ortaokul, Öğrenci. 


\title{
Research-Questioning Attitudes of Secondary School Students
}

\begin{abstract}
This research aims to investigate the research-questioning attitude levels of secondary school students. In accordance with this purpose, in this research the 'Research-Questioning Attitudes of Secondary School Students' scale and gender and grade level variables were used. 564 students participated in the research from all grade levels attending secondary school. The mean score of research-questioning attitude level of secondary school students was found to be $\bar{X}==2.03$ out of 5 . In addition, the mean score of curiosity sub-dimension was found to be $\bar{X}=1.81$, the avoiding sub-dimension was found to be $\bar{X}=$ 2.11 and signification sub-dimension was found to be $\bar{X}=2.16$. When the scale is analyzed, the KMO value was found to be .85 , Bartlett's test result was 1401.875. The Cronbach alpha coefficient value of the scale is .80. curiosity sub-dimension is .52, avoiding sub-dimension is .75 and signification subdimension is .66. According to the first finding of the research, the attitudes of secondary school students towards research-questioning differ significantly by gender $(p<.05)$. According to the second finding of the research, the attitudes of secondary school students towards research-questioning differ significantly by grade level $(p<.05)$ and these differences are between 5 th grade and 6 th grade; 5 th grade and 7 th grade and 5 th grade and 8 th grade.
\end{abstract}

Keywords: Research, Questioning, Attitude, Secondary School, Student. 


\section{Giriş}

Toplumlar tarihin her döneminde yeniliklerle karşı karşıya kalmış ve kendini güncelleyerek bulunduğu dönemde varlığını sürdürmeye devam etmişlerdir. Bulunduğu dönemin yeniliklerine uyum sağlayamayan toplumlar ise tarihte kendilerine yer bulamamıştır. Teknolojik gelişmeler, yapay zekâ, uzay ve havacılık bilimleri, insansız araçlar, endüstri 4, programlama ve yazılım, 21. yüzyıl toplumlarının karşılaştığı güncel kavramlar arasında yer almaktadır. Varlığını sürdürmek, ekonomisini güçlendirmek ve gelişmiş ülkeler sahnesinde yer almak isteyen toplumlar problem çözme becerisine sahip, araştıran ve sorgulayan, esnek ve yansitıcı düşünen, teknolojiyi etkin kullanan, öğrenmeyi öğrenen, takım çalışmasına uyumlu, eleştirel düşünebilen, iletişim kurabilen, kendini ifade eden (Şen ve Erişen, 2002), araştırma becerisine sahip, analitik ve eleştirel düşünebilen, problem çözebilen, bilgi ve iletişim teknolojilerinden etkin düzeyde yararlanan, kaynakları verimli kullanan (MEB, 2017), bağımsız çalışabilen, sorumluluk alan, iletişim becerisi güçlü, sosyal yetkinliklere sahip, bilgiye ulaşabilen, düşünen, anlayan, sorgulayan, sorun çözen (Güneş, 2012) ve özellikle de eğitim sistemleri aracıllğ̆ ile genç nesiller yetiştirmeyi amaçlamaktadır. Bu becerilere sahip bireyler yetiştirmeyi hedefleyen ve bu hedeflerine büyük oranda ulaşmayı başaran ülkeler tarihte kendilerine yer bulmuştur.

Günümüz toplumların geleceğine şekil veren, genç nesillerini yetiştiren, kültürel aktarımı sağlayan, yapıcı ve yaratıcı düşünme becerileri kazandıran, teknolojiyi etkin kullanan bireyler yetiştiren eğitim sistemleri öğrencilere aynı zamanda araştırma-sorgulama becerisi de kazandırır. Beceri bilginin uygulanması, problem durumların çözülmesi ve verilen görevlerin tamamlanmasıdır (Güneş, 2012). Öğretim programları hazır bilgiyi vermek yerine öğrencinin bilgiye araştırarak ulaşmasını amaçlamaktadır (Anagün ve Yaşar, 2009). Bu davranışın öğrenci tarafından edinilebilmesi için ise eğitim sistemleri tarafından araştırma olanaklarının oluşturulması öğrenciye araştırma becerilerinin kazandırılması hedeflenmektedir. Araştırma, bilinmeyen bilgiye ulaşma ve öğrenme, bilinir yapma ve aydınlatma süreci (Çalışkan, 2008), bilinmeyen bir konu ya da kavrama yönelik verilerin toplanması, toplanan verilerin analiz edilerek sonuçların 
raporlanması, ortaya çıkan sorunlara yönelik çözüm önerilerinin getirilmesidir (Alkan, 1989). Öğrencilere araştırma becerisini kazandırabilmek için problemin anlaşılması sağlanır ve çözümü için sistemli bir yöntem izlenir, öğrencilerin kendilerini yönlendirmeleri ve öğrenme süreçlerinin farkında olmaları sağlanır, öğrenilen bilgilerin uzun süre hafızada kalması ve transfer edilmesi amaçlanır (Arends, 1998). Araştırma becerisi kazanmış olan öğrencilerin araştırmaya dayalı bilgiyi üretmesi ya da bilgiye ulaşabilmesi için planlama, düzeltme, ilerleme, yaratma, paylaşma ve değerlendirme olmak üzere 6 aşamalı bir modeli uygulayabilir (Branch ve Oberg, 2004). Bu modele göre öğrenciler, planlama aşamasında konuyu belirleyerek plan oluşturur, düzeltme aşamasında kaynaklardan elde ettiği bilgileri düzenler, ilerleme aşamasında araştırmanın odağını oluşturur, yaratma aşamasında kaynaklardan elde ettiği bilgilerden bir bilgiye ulaşır, paylaşma aşamasında öğrenci elde ettiği bilgiyi dinleyicilerin görüşlerini alarak yeniden düzenler ve değerlendirme aşamasında araştırma sonucunda ulaşılan bilgiyi değerlendirir.

Eğitim sisteminin öğrencilere kazandırmak istediği bir diğer davranış ise sorgulama becerisidir. Sorgulama becerisi, öğrencilerin var olan bilgiyi olduğu gibi almasının ötesinde zihinde bir değerlendirme sürecinden geçirilmesi olarak ifade edilebilir. Başka bir ifadeyle sorgulama bilginin neden ve nasıllarının araştırılması ve ortaya çıkarılmasıdır. Temel öğrenme becerileri arasında yer alan araştırma becerisi; doğru sorular yönlendirerek problem anlama, ve kavrama, problemin çözümüne yönelik plan yapma, öngörüde bulunma, sonuçları değerlendirme ve fikir geliştirmeyi içerir (MEB, 2004). Sorgulama soru sormanın ötesinde öğrencilerin bilimin doğasına uygun olarak doğayı tanıma sürecinde kullandığı bilimsel etkinliklerdir (Crawford, 2007). Sorgulama düşünme, gelişme, yeni görüşler geliştirme ve mantıklı düşünme sürecidir (Bedir \& Duman, 2017). Sorgulama öğrencilerin akademik başarılarında ve bakış açılarında farklılık yaratacak nitelikte olmasından dolayı bir öğrenme becerisi olarak eğitimde yer edinmiş ve sorgulayıcı öğrenme becerisi olarak kavramlaştırılmış ve araştırmalara konu olmuştur.

Sorgulayıcı öğrenme becerisi bireyin merak duyduğu bir konu hakkında sorular yöneltmesi, bu sorulara cevaplar araması, bu süreçte yeni bilgilere ulaşması ya da üretmesi, bu bilgileri geniş kapsamda tartışması ve yansıtmasıdır (Taşkoyan, 2008). Sorgulayıcı öğrenme 
becerisi öğrencilerin bilgiye ulaşmak için araştırma-sorgulama yaptığ 1 ve bunun sonucunda kalıcı öğrenmenin sağlandığı yaşam boyu öğrenme becerisidir (Ekici, 2017). Sorgulamaya dayalı öğrenme bireyin zihinsel süreçlerini, ölçme, sinıflama, gözlem yapma, yorumlama, yordama, iletişim kurma, önceden tahmin etme, değişkenleri belirleme, hipotez oluşturma, sonuca ulaşma ve diğer düşünme biçimlerinden yararlanma becerilerini kullanmasıdır (Kor, 2003). Sorgulayıcı öğrenme öğrencilerin kavramsal öğrenmeleri desteklemesinin yanında öğrencilerin yaşantıları ile öğrendiklerini ilişkilendirmelerine fırsat tanıyan bir öğrenme modelidir (Stripling, 2008). Sorgulayıcı öğrenme sürecinde öğrenciler hipotez oluşturma ve test etme, etkenleri belirleme, değiştirme, kontrol etme ve tartışma etkinliklerine katılır (Gijlers, Saab, Van-Joolingen, DeJong \& Van Hout-Wolters, 2008).

Sorgulama becerisine dayalı öğrenme modeli; öğrenilenlere yönelik sorular oluşturmayı kapsayan problem tabanlı öğrenme, öğrenilen konunun proje araştırmalarıyla sunulması proje tabanlı öğrenme, karmaşık bir yapıda olan problemin planlı bir tasarım çalışması ile ortaya çıkarılması ve çözülmesi kapsamında tasarım tabanlı öğrenme uygulamalarını içerir (Stephenson, 2010). Sorgulayıcı öğrenme modeli merak etme, soruşturma, yapılandırma, açıklama, yansıtma ve ilişki kurma olmak üzere altı alt-boyuttan oluşmaktadır (Stripling, 2008).

Sorgulama becerisine dayalı öğrenme modeline yönelik çalışmalar yürütülmüş ve elde edilen sonuçlara bağlı olarak sınıflamalar yapılmıştır. McNeal ve D'Avanzo'a (1997) göre sorgulama becerisine dayalı öğrenme modeli güdümlü sorgulama, açlk uçlu sorgulama ve işbirlikçi sorgulama olmak üzere üç sınıfa ayrılır. Güdümlü sorgulamaya göre öğrencilerin sorgulama yapacakları konuya yönelik sorular öğretmen tarafından sağlanır ve denetlenir. Açık uçlu sorgulama türünde öğrenciler sorgulama sorularını ve yöntemini öğretmen gözetiminde oluşturur. İşbirlikçi sorgulama yönteminde ise öğretmen ve öğrenciler araştırma sorularını ve yöntemini birlikte oluştururlar. Carin, Bass ve Constant (2005) tarafından geliştirilen sorgulayıcı öğrenme modeli kılavuzlu keşfetme modeli, öğrenme halkası modeli, 5E öğrenme modeli ve kavramsal değişim modeli olmak üzere dört sınıfa ayrılmaktadır. Kılavuzlu keşfetme modeli öğrencinin keşfetme yaklaşımına göre öğrenmesini ve öğretmenin de açıklamalarla öğrenciyi yönlendirmesini ifade eder. Öğrenme halkası 
modeli araştırma, kavram tanıtımı ve kavram uygulaması aşamalarından oluşan ve öğrencilerin bilimsel kavramları anlamasını kolaylaştırmayı amaçlayan sorgulayıcı öğrenme modelidir. 5E öğrenme modeli girme, keşfetme, açıklama, derinleştirme ve değerlendirme aşamalarından oluşan ve öğrencilerin bu aşamaları kullanarak sonuca varmasını amaçlayan sorgulayıcı öğrenme modelidir. Kavramsal değişim modeli öğrencinin tanıtım, gözden geçirme, gelişim, araştırmalar ve etkinlikler, sunum, tartışma ve özet olmak üzere 7 aşamada sonuca varmasını amaçlayan sorgulayıcı öğrenme modelidir. Colburn (2000) sorgulamaya dayalı öğrenmeyi yapılandırılmış sorgulama, kılavuzlu sorgulama ve açık sorgulama olmak üzere üç sınıfta incelemiştir. Yapılandırılmış sorgulama gerekli olan araçların öğretmen tarafından hazırlanması ve öğrencilerin bu araçları kullanarak sonuca ulaşmasıdır. Kılavuzlu sorgulama, öğretmenlerin öğrenciler tarafından yapılacak olan sorgulama sürecini desteklemesi ve öğrencileri gelecekte bireysel sorgulama sürecine hazırlamasıdır. Açık sorgulama ise sorgulama sorularının hazırlanması, yönteminin öğrenciler tarafından belirlenmesi ve yine cevapların öğrenciler tarafından verilmesidir.

Modele dayalı sorgulayıcı öğrenmenin sağlanabilmesi için birtakım öğretmen ve öğrenci davranışlarının olduğu araştırmacılar tarafından ortaya konulmuştur. Araştırma-sorgulama becerisinin tüm toplumların ve özellikle eğitim örgütlerinde kazanılması beklenen 21. yüzyıl davranışları arasında olduğu görülmektedir. Bu bağlamda öğrencilerin sorgulayıcı öğrenme rolleri uygun materyalleri, etkinlik ve nesneleri bir araya getirmek, mantıklı sorular oluşturmak, grup çalışması ve işbirliği yapmak, fikirleri paylaşmak, uygun ölçme araçları geliştirmek, elde edilen bilgileri diğer bilgiler ile karşılaştırmak, araştırma sürecini planlamak, gözlem yapmak ve sunmak, araştırma-sorgulama sonucunda elde edilen bulguları kaydetmek, araştırma sürecinde grafik, gösterge ve tablolardan yararlanmak olarak sıralanabilir. Öğretmenlerin sorgulayıcı öğrenme rolleri öğrencilerin araştırma yapabilmeleri için gerekli araç, gereç ve materyal sağlamak, bu materyallerin kullanımlarını öğrencilere detaylı şekilde açılamak, önceki öğrenmeleri ortaya çıkarmak ve onlardan yararlanmak, öğrencilerin fikir üretmesi için uygun ortamlar oluşturmak, bu fikirleri test etmek, öğrencilere öğrenme sorumluluğu 
kazandırmak, öğrencilere güvenli çalışma ortamı oluşturmak ve öğrencileri cesaretlendirmek olarak sıralanabilir.

$\mathrm{Bu}$ araştırma ile ortaokulun tüm kademelerinde öğrenim görmekte olan öğrencilerin araştırma-sorgulama tutumlarının saptaması amaçlanmıştır. Bu kapsamda,

1. Ortaokul öğrencilerinin araştırma-sorgulama tutum düzeyleri,

2. Ortaokul öğrencilerinin cinsiyet değişkenine göre araştırmasorgulama tutum düzeyleri,

3. Ortaokul öğrencilerinin sınıf düzeyi değişkenine göre araştırmasorgulama tutum düzeyleri ortaya çıkarılacaktır.

\section{Yöntem}

\section{Araştırmanın Metodu}

$\mathrm{Bu}$ araştırma nicel bir çalışma olup ortaokul öğrencilerinin araştırmasorgulama becerilerini tarama modeliyle belirlemeyi amaçlamaktadır. Nicel araştırma yöntemleri olgu ve olayları sayısallaştırarak ölçülebilir ve analiz edilebilir bir şekilde açılayan araştırma türüdür (Fraenkel \& Wallen, 2009). Tarama modeli geçmişte ya da halen var olan bir durumu değiştirmeden ve etkilemeden olduğu hali ile betimlemeyi amaçlayan araştırmalara uygun bir modeldir (Karasar, 2014). Bu kapsamda bu araştırma ile ortaokul öğrencilerinin araştırma-sorgulama becerileri sayısal verilere dönüştürülerek var olan haliyle analiz edilecektir.

\section{Evren-örneklem}

$\mathrm{Bu}$ araştırmanın evreni ortaokul kademesinin tüm sınıflarında öğrenim gören öğrencilerden oluşmaktadır. Araştırmanın örneklemini ortaokul düzeyinde öğrenim gören 564 öğrenci oluşturmaktadır. Araştırmanın örneklemine yönelik demografik bilgiler Tablo 1'de verilmiştir.

Tablo 1. Ortaokul öğrencilerinin demografik özellikleri

\begin{tabular}{llll}
\hline Değişken & Kategori & f & \% \\
\hline \multirow{2}{*}{ Cinsiyet } & kız & 284 & 50.4 \\
& Erkek & 280 & 49.6 \\
\hline Sinıf Düzeyi & 5. Sinıf & 143 & 25.4
\end{tabular}




\begin{tabular}{llll}
\hline & 6. Sinif & 136 & 24.1 \\
& 7. Sinif & 145 & 24.8 \\
& 8. Sinif & 140 & 25.7 \\
\hline Toplam & 564 & 100 \\
\hline
\end{tabular}

Tablo 1 incelendiğinde araştırmaya toplam $284(\% 50,4) \mathrm{k}$ ız ve 280 $(\% 49,6)$ erkek öğrenci olmak üzere toplamda 564 ortaokul öğrencisinin katılım gösterdiği görülmektedir. Araştırmada, 143 öğrenci 5. sınıf $(\% 25,4), 136$ öğrenci 6. sinıf $(\% 24,1), 145$ öğrenci 7. $(\% 24,8)$ sinıf ve 140 öğrenci 8. sinıf $(\% 25,7)$ düzeyinde öğrenim görmektedir. Demografik dağılım incelendiğinde dağılımın birbirine oldukça yakın olduğu görülmektedir. Bu durumun araştırma sonucunda tutarlı bulgulara ulaşılmasında önemli bir etken olduğu söylenebilir.

\section{Veri Toplama Aracı ve Verilerin Toplanması}

Araştırma verileri resmi izinler alınarak 15 gün süre içinde ve elden toplanmıştır. Araştırma öncesi öğrencilere araştırmaya yönelik açıklamalar yapılmış, kimlik bilgileri ile araştırmada verilen cevapların gizliliği vurgulanmıştır. Araştırmada Ozan, Korkmaz ve Karamustafaoğlu (2016) tarafından geliştirilen ortaokul öğrencilerine yönelik 'Araştırma-Sorgulamaya Yönelik Tutum Ölçeği' kullanılmıştır. Ölçek merak duyma $(1,2,3,4)$, kaçınma $(5,6,7,8$, 9) ve değer verme (10, $11,12,13)$ olmak üzere 3 alt-boyut ve 13 maddeden oluşmaktadır. Araştırmada kullanılan veri toplama aracı 5'li likert tipindedir ve derecelendirme aralıkları; 5-Hiç katılmıyorum, 4- Katılmıyorum, 3Kararsızım, 2- Katılıyorum, 1-Tamamen katılıyorum olarak sıralanmıştır. Ölçeğe uygulanan geçerlilik ve güvenirlik analizleri incelendiğinde ölçeğin KMO değeri .85, Bartlett's testi sonucu 1401.875 ve Cronbach alpha katsayı değeri .80 olarak bulunmuştur. Ölçeğin merak duyma altboyutunda Cronbach alpha katsayı değeri .52, kaçınma alt-boyutunda Cronbach alpha katsayı değeri .75 ve değer verme alt-boyutunda Cronbach alpha katsayı değeri .66 olarak bulunmuştur. 


\section{Verilerin Analizi}

Araştırma nicel yöntemle yapılmıştır, elde edilen veriler analize uygun hale dönüştürülmüş ve SPSS programı ile analiz edilmiştir. Normal dağılım gösteren verilerin \pm 1.0 aralığında olması beklenir (Çokluk, Şekercioğlu ve Büyüköztürk, 2014; Gürbüz ve Şahin, 2014; Hair, Black, Babin, Anderson ve Tatham, 2013). Araştırma verilerine yapılan normallik dağılımı analizi sonucunda basıklık çarpıklık değerlerinin normal dağılım ( \pm 1.0$)$ aralığında olduğu görülmüştür. Cinsiyet değişkenine parametrik analiz türlerinden $t$ testi ve sinıf düzeyi değişkenine parametrik analiz türlerinden Tek-Yön ANOVA testi uygulanmıştır. Analiz sonucunda elde edilen bulgular aşağıda sırayla verilmiştir.

\section{Bulgular}

Ortaokul öğrencilerinin araştırma-sorgulama tutumlarını ölçmeye yönelik yapılan bu araştırmanın bulguları aşağıda verilmiştir.

Tablo 2. Ortaokul öğrencilerinin araştırma-sorgulama tutumlarına yönelik betimsel özellikler

\begin{tabular}{ll}
\hline Değişkenler & Araştırma-sorgulama tutum düzeyi \\
\hline $\mathrm{N}$ & 564 \\
$\mathrm{X}$ & 2.03 \\
$\mathrm{Ss}$ & .65 \\
$\mathrm{Ky}$ & .100 \\
$\mathrm{SE}\left(\mathrm{K}_{\mathrm{y}}\right)$ & .205 \\
$\mathrm{BS}$ & .647 \\
$\mathrm{SE}\left(\mathrm{B}_{\mathrm{s}}\right)$ & .103 \\
\hline
\end{tabular}

Tablo 2'de ortaokul öğrencilerinin araştırma-sorgulama tutum düzeylerinin saptanmasına yönelik kullanılan ölçeğin betimsel istatistikleri yer almaktadır. Ortaokul öğrencilerinin araştırma-sorgulama tutum düzeyi ortalama puanı $\bar{X}=2.03$ bulunmuştur. Ayrıca ölçeğin merak duyma merak duyma alt-boyutu ortalama puanı $\bar{X}=1.81$, kaçınma altboyutu ortalama puan $\bar{X}=2.11$ ve değer verme alt-boyutu ortalama puanı $\bar{X}=2.16$ olarak bulunmuştur. Ortaokul öğrencilerinin cinsiyete göre araştırma-sorgulama tutum düzeylerini ortaya çıkarmak için yapılan $t$ testi sonuçları aşağıda Tablo 3'te verilmiştir. 
Tablo 3. Ortaokul öğrencilerinin cinsiyete göre araştırma-sorgulama tutum düzeyleri

\begin{tabular}{llllllll}
\hline Değişken & Kategori & $\mathbf{N}$ & $\overline{\mathbf{X}}$ & ss & $\mathbf{d f}$ & $\mathbf{t}$ & $\mathbf{p}$ \\
\hline \multirow{2}{*}{ Cinsiyet } & Kız & 284 & 1.97 & .651 & \multirow{2}{*}{562} & -2.395 & \multirow{2}{*}{.017} \\
\cline { 2 - 8 } & Erkek & 280 & 2.10 & .655 & & & \\
\hline
\end{tabular}

Ortaokul öğrencilerinin cinsiyete göre araştırma-sorgulama tutum düzeylerini ortaya çıkarmak için $t$ testi yapılmıştır. Tablo 3 incelendiğinde ortaokul öğrencilerinin cinsiyete göre araştırma-sorgulama tutum düzeyleri arasında anlamlı bir farklılık vardır $\left(t_{(562)}=-2.395\right)$. Başka bir ifadeyle öğrencilerin araştırma-sorgulama tutumları cinsiyete göre değişmektedir. Alt-boyutlarda öğrencilerin cinsiyete göre araştırmasorgulama tutum düzeyleri incelendiğinde merak duyma alt-boyutunda öğrencilerin cinsiyete göre araştırma-sorgulama tutum düzeyleri arasında anlamlı bir farklılık yoktur ( $\mathrm{p}>$.05). Kaçınma alt-boyutunda öğrencilerin cinsiyete göre araştırma-sorgulama tutum düzeyleri arasında anlamlı bir farklılık vardır ( $\mathrm{p}<.05)$. Değer verme alt-boyutunda öğrencilerin cinsiyete göre araştırma-sorgulama tutum düzeyleri arasında anlamlı bir farklılık yoktur ( $\mathrm{p}>$.05). Ortaokul öğrencilerinin sinıf düzeyine göre araştırmasorgulama tutum düzeylerini ortaya çıkarmak için yapılan Tek-Yön ANOVA testi sonucu aşağıda Tablo $4^{\prime}$ te verilmiştir.

Tablo 4. Ortaokul öğrencilerinin sınıf düzeyine göre araştırma-sorgulama tutum dïzeyleri

\begin{tabular}{lllllll}
\hline Değişken & $\begin{array}{l}\text { Varyansın } \\
\text { Kaynağı }\end{array}$ & $\begin{array}{l}\text { Kareler } \\
\text { Toplamı }\end{array}$ & df & $\begin{array}{l}\text { Kareler } \\
\text { Ortalaması }\end{array}$ & F & p \\
\hline \multirow{2}{*}{ Sınıf Düzeyi } & Genel & 242.647 & 563 & 2.548 & .072 & .000 \\
& Gruplar arası & 7.645 & 3 & .420 & \\
\hline
\end{tabular}

Ortaokul öğrencilerinin sınıf düzeyine göre araştırma-sorgulama tutum düzeylerini ortaya çıarmak için Tek-Yön ANOVA testi yapılmıştır. Tablo 4 incelendiğinde ortaokul öğrencilerinin sınıf düzeyi değişkenine göre araştırma-sorgulama tutum düzeyleri arasında anlamlı bir farklılığın olduğu görülmektedir ( $\mathrm{p}<.05)$. Bu anlamlı farklılığın hangi ikili gruplar arasında olduğunu ortaya çıkarmak için yapılan tukey testi sonucunda anlamlı farklıliklarin 5.sinıf ile 6.sinif, 5.sinif ile 7. sinıf ve 5. sinif ile 8 sinıflar arasında olduğu görülmektedir. Aşağıda Tablo 5'te ortaokul 
öğrencilerinin araştırma-sorgulama tutum düzeyleri madde ortalama puanları verilmiştir.

Tablo 5. Ortaokul öğrencilerinin araştırma-sorgulama tutum düzeyleri madde ortalama puanlarn

\begin{tabular}{lll}
\hline Sıra & Madde & $(\overline{\mathbf{X}})$ \\
\hline 1. & Kafama takılan sorulara cevap bulmayı isterim. & 1.49 \\
2. & Tartışılan bir konu hakkında bilmediklerimi çekinmeden sorarım. & 2.20 \\
3. & Hayatımızı kolaylaştıracak araştırmalar yapmayı isterim. & 1.73 \\
4. & Herhangi bir şey okurken okuduklarımın doğru olup olmadığını düşünürüm. & 1.85 \\
5. & Araştırma yapmak bazen zaman kaybıdır. & 2.21 \\
6. & Araştırmalar ilgi alanıma girmez. & 2.03 \\
7. & Çabuk sonuçlandırılmayan araştırmalar gereksiz araştırmalardır. & 2.11 \\
8. & Bir araştırma ödevi verildiğinde kendimi kötü hissederim. & 2.01 \\
9. & Arkadaşlarımla bir grup kurarak araştırma yapmak bana saçma geliyor. & 2.16 \\
10 & Araştırmalar hayatımızı kontrol etmemizi sağlar. & 2.20 \\
11. & Hayatın araştırmalarla dolu olduğuna inanmam. & 3.57 \\
12. & Araştırmaların dikkat gerektirdiğini düşünmem. & 3.94 \\
13. & Araştırmanın hayatımızda önemli bir parça olduğuna inanırım. & 1.95 \\
\hline
\end{tabular}

Ortaokul öğrencilerinin araştırma-sorgulama tutum düzeyleri ortalama puanı $(\overline{\mathrm{X}})=2.03$ olarak bulunmuştur. Tablo 5 incelendiğinde madde ortalama puanlarının $\bar{X}=1.49$ ile $\bar{X}=3.94$ aralığında olduğu görülmektedir. Ölçeğin $1,3,4$ ve 13 . maddeleri $\bar{X}=1.49$ ile $\bar{X}=1.95$ ortalama puan aralığında, $2,5,6,7,8,9$ ve 10 . maddeleri $\bar{X}=2.01$ ile $\bar{X}=2.21$ ortalama puan aralığında ve 11 ve 12 . maddelerin $\bar{X}=3.57$ ile $\bar{X}=3.94$ ortalama puan aralığında olduğu görülmektedir.

\section{Tartışma ve Sonuç}

$\mathrm{Bu}$ araştırma ile ortaokul öğrencilerinin araştırma-sorgulama düzeyleri ortaya çıkarılmaya çalışılmıştır. Bu kapsamda araştırma nicel araştırma türlerinden tarama modelinde yürütülmüştür. Araştırmada ortaokul öğrencilerinin araştırma-sorgulamaya yönelik tutum ölçeği ile cinsiyet ve sınıf düzeyi değişkenleri kullanılmıştır.

Araştırmanın birinci bulgusuna göre ortaokul öğrencilerinin araştırma-sorgulamaya yönelik tutum düzeyleri $\overline{\mathrm{X}}=2.03$ bulunmuştur. Öğrencilerin araştırma-sorgulama tutum düzeylerini ortaya çıkarmaya yönelik benzer araştırmalar cinsiyet ve sınıf düzeyi değişkenleri açısından incelenmiştir. 
Araştırmanın ikinci bulgusuna göre ortaokul öğrencilerinin araştırma sorgulamaya yönelik tutum düzeyleri cinsiyete göre anlamlı farklılık göstermektedir ve bu farklılık erkek öğrencilerin lehinedir $(\mathrm{p}<.05)$. Öğrencilerin cinsiyet açısından araştırma-sorgulama becerilerine yönelik benzer çalışmalar incelendiğinde, Böyük, Tanık ve Saraçoğlu (2011) öğrencilerin bilimsel düşünme becerilerinde cinsiyete göre anlamlı farklılığın olduğunu ifade etmiştir. Ekici (2017), ortaokul öğrencilerinin bilimsel sorgulama beceri algılarını etkileyen faktörleri incelemeye yönelik yaptığı araştırmada cinsiyetin ortaokul öğrencilerinin sorgulama becerilerinde anlamlı bir farklılık oluşturduğu sonucuna ulaşmıştır. Yaman ve Dede (2007) tarafından yapılan araştırmada cinsiyetin fen ve matematik derslerine yönelik öğrenme becerilerinde anlamlı farklılık oluşturduğu ve bu farklılığın kız öğrencilerin lehine olduğu sonucuna ulaşılmıştır. Bozkurt ve Çakır (2016) tarafından yapılan ortaokul öğrencilerinin 21. yüzyıl öğrenme beceri düzeylerine yönelik araştırmada kız öğrencilerin ortalama puanlarının tüm düzeylerde erkek öğrencilere oranla daha yüksek olduğu sonucuna ulaşılmıştır. Başka bir ifadeyle kız öğrencilerin araştırma-sorgulama becerisini de kapsayan 21. yüzyıl becerilerinde daha başarılı olduğu söylenebilir. Öztürk, Bilgen ve Bilgen (2017) öğrencilerin sorgulama becerileri ile kendi kendine öğrenme becerileri arasındaki ilişkiyi ortaya çıkarmaya yönelik yaptığı araştırmada cinsiyetin öğrencilerin sorgulama becerilerinde anlamlı bir fark oluşturmadığı sonucuna ulaşmıştır. Kaya ve Yılmaz, (2016) açık sorgulamaya dayalı öğrenmeye yönelik yaptığı araştırmada cinsiyet ile sorgulama becerisi arasında anlamlı bir ilişkinin olmadığ 1 sonucuna ulaşmıştır. Kardemir (2016) öğretmen adaylarının sorgulama ve eleştirel düşünme becerilerine yönelik yaptığ1 çalışmada cinsiyet değişkeninin sorgulama açısından önemli fark oluşturmadığını ifade etmiştir. Weinburg (1995) öğrencilerin fen bilimlerine yönelik tutumları arasında anlamlı bir farkın olduğu ve bu farkın kız öğrencilerin lehine olduğu sonucuna ulaşmıştır. Jones, Howe ve Rua, (2000) öğrencilerin fen eğitimine yönelik tutumlarını araştırdığı çalışmada kadın öğrencilerin fen eğitimini erkek öğrencilere göre oldukça zor bulduğu ifade etmiştir. Spelke (2005) kadın ve erkek öğrencilerin matematik ve fen bilimlerine yönelik yakın düzeyde tutuma sahip olduğu ancak erkek öğrencilerin matematik becerilerinin daha yüksek olduğu sonucuna ulaşmıştır. Işık ve 
Yenice (2012) ortaokul öğrencilerinin öğrenme stilleri ile sorgulayıc1 öğrenme becerilerine yönelik çalışmasında cinsiyetin öğrencilerin sorgulama becerisinde anlamlı bir fark oluşturmadığını belirtmiştir.

Araştırmanın üçüncü bulgusuna göre ortaokul öğrencilerinin araştırma-sorgulamaya yönelik tutumları sinıf düzeyine göre anlamlı farklılık göstermektedir ( $\mathrm{p}<.05)$ ve bu farklılık 5. sinıf ile 6. Sinıf, 5.sinıf ile 7. sınıf ve 5 . sınıf ile 8 sınıflar arasında olduğu görülmektedir. Öğrencilerin sınıf düzeyi açısından araştırma-sorgulama becerileri diğer çalışmalarda incelendiğinde Böyük, Tanık ve Saraçoğlu (2011) ilköğretim ikinci kademe öğrencilerinin bilimsel düşünme becerilerinde sınıf düzeyine göre anlamlı farklılık olduğu sonucuna ulaşmıştır. Ekici (2017) ortaokul öğrencilerinin bilimsel sorgulama beceri algılarını etkileyen faktörleri incelemeye yönelik yaptığı araştırmada sınıf düzeyinin ortaokul öğrencilerinin sorgulama becerilerinde anlamlı bir farklılık oluşturduğu sonucuna ulaşmıştır. Yaman ve Dede (2007) tarafından yapılan araştırmada sınıf düzeyinin fen ve matematik derslerine yönelik öğrenme becerilerinde anlamlı farklılık oluşturduğu, bu farklılı̆̆ın 6. sınıf öğrencilerin lehine olduğu ve bu düzeydeki öğrencilerin üst sınıftaki öğrencilere göre araştırma, iletişim ve katılım becerilerinin daha yüksek olduğu sonucuna ulaşılmıştır. Işık ve Yenice (2012) ortaokul öğrencilerinin öğrenme stilleri ile sorgulayıcı öğrenme becerilerine yönelik çalışmasında sınıf düzeyinin öğrencilerin sorgulama becerisinde anlamlı bir fark oluşturmadığ görülmüştür. Meißner, Greiff, Frischkorn ve Steinmayr (2016) problem çözme becerilerine yönelik araştırmasında sınıf düzeyinin öğrencilerin bilişsel süreçlerinin ve motivasyonlarının önemli yordayıcıları olduğu sonucuna ulaşmıştır.

21. yüzyıl becerileri arasında yer alan araştırma-sorgulama becerilerinin ortaokul öğrencilerine kazandırılması beklenmektedir. Bu nedenle öğrencilere araştırma-sorgulama kavramı ve önemi detaylı bir şekilde anlatılarak bir davranış haline getirilebilir. Ayrıca öğrencilerin karşılaştıkları bir problem durumunu tüm detayları ile ortaya çıkarma, doğru sorular sorma, amaca uygun planlar yapma ve sonuca ulaşmada doğru yöntemleri seçme ve araç-gereci sağlama davranışları kazandırılabilir. Bunun yanında öğrencilere problem durum ile ilgili doğru kaynaklara ulaşma, fikir alışverişinde bulunma, problemi tartışma, farklı yöntemler deneme ve bakış açılarını geliştirme becerileri kazandırılabilir. 


\title{
EXTENDED ABSTRACT \\ Research-Questioning Attitudes of Secondary School Students
}

\author{
* \\ Mehmet Özcan \\ Hacı Bektaşı Veli University
}

\section{Introduction}

Societies have faced innovations in every period of history and have continued to exist in the period when they have update themselves. Societies that could not adapt to the innovations of the period disappeared from history. Technological developments, artificial intelligence, space and aviation sciences, industry 4 , programming and software are among the current concepts faced by 21 st century societies. Societies that want to continue their existence, strengthen their economy and take part in the stage of developed countries have problem-solving, research and questioning skills, think flexibly and reflectively, use technology effectively, learn how to learn, adapt to teamwork, think critically, communicate and express themselves (Şen and Erişen, 2002) have research skills, can think analytically and critically, can solve problems, can make use of information and communication technologies effectively, use resources efficiently (MoNE, 2017), work independently, take responsibility, have strong communication skills, have social competencies, and have access to information. This aims to raise individuals who think, understand, question, and solve problems (Güneş, 2012) and especially young generations through education systems. Countries that aim to raise individuals with these skills and achieve these goals to a large extent are certain to persist on the stage of history.

\section{Method}

This research is a quantitative study and aims to determine the researchquestioning skills of secondary school students with survey model. In this context, with this research, the research-questioning skills of secondary school students will be transformed into numerical data and analysed as 
they exist. The participants of this research consists of students studying in all secondary school levels. The sample of the study consists of 564 students studying at secondary school. Research data were collected within 15 days, with official permissions. In the research, the 'Research-Questioning Attitudes of Secondary School Students' scale for secondary school students developed by Ozan, Korkmaz and Karamustafaoğlu (2016) was used. When validity and reliability analyzes applied to the scale were examined, the KMO value of the scale was found to be .85 , Bartlett's test result was found to be 1401.875 and Cronbach alpha coefficient value was found to be .80 . The Cronbach alpha coefficient value was found to be .52 in the curiosity sub-dimension of the scale, the Cronbach alpha coefficient value was found to be .75 in the avoiding sub-dimension, and the Cronbach alpha coefficient value in the signification sub-dimension was found to be .66. The research was carried out with quantitative method. As a result of the normality distribution analysis performed on the research data, it was seen that the kurtosis skewness values were within the normal range $( \pm 1.0)$. $t$ test and One-Way ANOVA test were applied to the gender variable and to the grade level variable.

\section{Results}

The descriptive statistics of the scale used to determine the research-questioning attitude levels of secondary school students are included. Secondary school students' research-questioning attitude level average score was found to be $\bar{X}=2.03$. In addition, the curiosity sub-dimension mean score was found to be $\bar{X}=1.81$, the avoiding sub-dimension mean score was found to be $\bar{X}=2.11$, and the signification sub-dimension mean score was found to be $\bar{X}=2.16$. A t-test was used to reveal the research-questioning attitude levels of secondary school students according to gender. When Table 3 is examined, there is a significant difference between the researchquestioning attitude levels of secondary school students according to gen$\operatorname{der}\left(t_{(562)}=-2.395\right)$. In other words, students' research-questioning attitudes differ according to gender. When the research-questioning attitude levels of the students according to gender are examined regarding the sub-dimensions, there is no significant difference between the research-questioning attitude levels of the students according to the gender in the curiosity 
and signification sub-dimensions ( $\mathrm{p}>$.05). In the avoiding sub-dimension, however, there is a significant difference between the research-questioning attitude levels of students according to gender $(\mathrm{p}<.05)$. One-Way ANOVA test was conducted to reveal the research-questioning attitude levels of secondary school students according to their grade level. When Table 4 is examined, it is seen that there is a significant difference between the research-questioning attitudes of secondary school students according to the grade level variable $(\mathrm{p}<.05)$. As a result of the tukey test conducted to reveal between which pair groups this significant difference exists, the significant differences were found between 5 th grade and 6 th grade, 5 th grade and 7th grade and 5th grade and 8th grade. Secondary school students' research-questioning average score was found to be $\bar{X}=2.03$. When Table 5 is examined, it is seen that the average scores of the items are between $\bar{X}=1.49$ and $\bar{X}=3.94$. Items $1,3,4$, and 13 of the scale are between $\bar{X}=1.49$ and $\bar{X}=1.95$ mean score range, items $2,5,6,7,8,9$ and 10 are between $\bar{X}=2.01$ and $(\bar{X})=2.21$ mean score range, and items 11 and 12 are between $\bar{X}=3.57$ and $\bar{X}=3.94$ mean scores range.

\section{Conclusion}

Secondary school students' research-questioning skills are expected to be acquired in the 21st century and research studies have been conducted for this purpose. Therefore, it can be turned into a behavior by explaining the concept of research-questioning and its importance in detail to the students. In addition, students can be taught to reveal a problem situation in all its details, to ask the right questions, to make appropriate plans and to provide the necessary methods, tools and materials to obtain the result. In addition, students can gain the skills of accessing the right sources about the problem situation, exchanging ideas, discussing the problem, trying different methods and developing their perspectives.

\section{Kaynakça / References}

Alkan, C. (1989). Eğitim bilimlerinde araştırma. Ankara Üniversitesi Ĕ̆itim Bilimleri Fakültesi Dergisi, 22(1), 23-27. 
Anagün, Ş. S. ve Yaşar, Ş. (2009). İlköğretim beşinci sınıf fen ve teknoloji dersinde bilimsel süreç becerilerinin geliştirilmesi. İlköğretim Online, 8(3), 843-865.

Arends, J. (1998). Learning to teach. New York: McGraw-Hill Company.

Bedir, T. ve Duman, B. (2017). Öğretmen adaylarının sorgulama becerilerinin incelenmesi. Turkish Studies, 12(18), 105-120.

Bozkurt, Ş. B. ve Çakır, H. (2016). Ortaokul öğrencilerinin 21. yüzyı öğrenme beceri düzeylerinin cinsiyet ve sinıf seviyesine göre incelenmesi. Pamukkale Üniversitesi Eğitim Fakültesi Dergisi, 39(39), 6982.

Böyük, U., Tanık, N. ve Saraçoğlu, S. (2011). İlköğretim ikinci kademe öğrencilerinin bilimsel süreç beceri düzeylerinin çeşitli değişkenler açısından incelenmesi. Tübav Bilim Dergisi, 4(1), 20-30.

Branch, J. ve Oberg, D. (2004). Focus on inguiry, a teacher's guide to implementing inquiry-based learning. Canada: Learning Resources Centre.

Carin, A., Bass, J. E. ve Contant, T. L. (2005). Teaching science as inquiry. Upper Saddle River, NJ: Pearson Education, Inc.

Colburn, A. (2000). An inquiry primer. Science Scope, 23(6),42-44.

Crawford, A. B. (2007). Learning to teach science as inquiry in the rough and tumble of practice. Journal of Research in Science Teaching, 44(4), 613642.

Çalışkan, H. (2008). İköğretim 7. sımı sosyal bilgiler dersinde araştırmaya dayalı öğrenme yaklaşımının derse yönelik tutuma, akademik başarıya ve kahıllık düzeyine etkisi (Yayınlanmamış Doktora Tezi). Gazi Üniversitesi Eğitim Bilimleri Enstitüsü, Ankara.

Çokluk, Ö., Şekercioğlu, G. ve Büyüköztürk, Ş. (2014). Sosyal bilimler için çok değişkenli istatistik SPSS ve LISREL uygulamaları. Ankara: Pegem Akademi Yayınları.

Ekici, D. İ. (2017). Ortaokul öğrencilerinin bilimsel sorgulama becerileri algılarını etkileyen faktörlerin incelenmesi. Kastamonu Eğitim Dergisi, 25(2), 497-516.

Fraenkel, J. R. ve Wallen, N. E. (2009). How to design and evaluate research in education. New York, NY: McGraw-Hill.

Gijlers, H., Saab, N., Van Joolingen, W. R., De Jong, T. ve Van Hout-Wolters, B.H. (2009). Interaction between tool and talk: How instruction and tools support consensus building in collaborative inquiry-learning environments. Journal of Computer Assisted Learning, 25, 252-267. 
Güneş, F. (2012). Bologna süreci ile yükseköğretimde öngörülen beceri ve yetkinlikler. Yüksekögretim ve Bilim Dergisi, 2(1), 1-9.

Gürbüz, S ve Şahin, F. (2014). Sosyal bilimlerde araştırma yöntemleri. Ankara: Seçkin Yayıncılık.

Hair, J. F., Black, W. C., Babin, B. J., Anderson, R. E. ve Tatham, R. L. (2013). Multivariate data analysis. Essex: Pearson Education Limited.

Işık, G. ve Yenice, N. (2012). İlköğretim ikinci kademe öğrencilerinin öğrenme stilleri ile sorgulayıcı öğrenme becerileri arasındaki ilişkinin belirlenmesi. Adnan Menderes Üniversitesi Eğitim Fakültesi Eğitim Bilimleri Dergisi, 3(1), 60-73.

Jones, M. G., Howe, A. ve Rua, M. J. (2000). Gender differences in students' experiences, interests, and attitudes toward science and scientists. Science Education, 84(2), 180-192.

Karademir, Ç. A. (2013). Öğretmen adaylarının sorgulama ve eleştirel düşünme becerilerinin öğretmen öz yeterlik düzeyine etkisi (Yayınlanmamış Doktora Tezi). Adnan Menderes Üniversitesi, Sosyal Bilimler Enstitüsü, Aydın.

Karasar, N. (2014). Bilimsel araştırma yöntemleri: Kavramlar, teknikler ve ilkeler. Ankara: Nobel Yayınevi.

Kaya, G. ve Yılmaz, S. (2016). Açık sorgulamaya dayalı öğrenmenin öğrencilerin başarısına ve bilimsel süreç becerilerinin gelişimine etkisi. Hacettepe Üniversitesi Ĕ̆̈itim Fakültesi Dergisi, 31(2), 300-318.

Kor, F. (2003). Ilköğretim 8. sinıf öğrencilerinde, sınıf içi aktivitelerin, problem çözmeye etkisi; hücre bölünmeleri (Yayımlanmamış Yüksek Lisans Tezi). Marmara Üniversitesi, Eğitim Bilimleri Enstitüsü, İstanbul.

McNeal A.P. ve D'Avanzo C. (1997). Student-active science: Models of innovation in college science teaching. Fort Worth, TX: Saunders College.

MEB (2004). Tebliğler Dergisi (2563). Erişim adresi: http://tebligler.meb.gov.tr/index.php/tuem-sayilar/viewcategory/68$\underline{2004}, 01.10 .2021$.

MEB (2017). İlköğretim ve ortaöğretim öğretim programlarının güncellenmesi. Erişim adresi: https://ttkb. meb. gov. tr/www/ilkogretim-veortaogretim-ogretim-programlarinin guncellenmesi/icerik/289. 01.10.2021.

Meißner, A., Greiff, S., Frischkorn, G. T. ve Steinmayr, R. (2016). Predicting complex problem solving and school grades with working memory 
and ability self-concept. Learning and Individual Differences, 49, 323331.

Ozan, C. E., Korkmaz, Ö. ve Karamustafaoğlu, S. (2016). Ortaokul öğrencilerinin araştırma-sorgulamaya dönük tutum ölçeği. Amasya Üniversitesi Ĕ̆itim Fakültesi Dergisi, 5(2), 483-509.

Öztürk, Y. A., Bilgen, Z. ve Bilgen, S. (2017). Sorgulama becerileri ile kendi kendine öğrenme becerileri arasındaki ilişki: Temel eğitim öğretmen adaylarına yönelik bir araştırma. Sinop Üniversitesi Sosyal Bilimler Dergisi, 1(2), 179-214.

Spelke, E. S. (2005). Sex differences in intrinsic aptitude for mathematics and science? A critical review. American Psychologist, 60(9), 950-958.

Stephenson, N. (2010). Introduction to inquiry based learning. Erişim adresi: http://www.teachinquiry.com/index/Introduction.html.

Stripling, B. (2008). Inquiry: Inquiring minds want to know. School Library Media Activities, 25(1), 50-52.

Şen, H. S. ve Erişen, Y. (2002). Öğretmen yetiştiren kurumlarda öğretim elemanlarının etkili öğretmenlik özellikleri. Gazi Ĕ̆itim Fakültesi Dergisi, 22(1), 99-116.

Taşkoyan, N.S. (2008). Fen ve teknoloji öğretiminde sorgulayıcı öğrenme stratejilerinin öğrencilerin sorgulayıcı öğrenme becerileri, akademik başarıları ve tutumları üzerindeki etkisi (Yayınlanmamış Yüksek Lisans Tezi). Dokuz Eylül Ün,versitesi, Eğitim Bilimleri enstitüsü, İzmir.

Weinburgh, M. (1995). Gender differences in student attitudes toward science: A meta-analysis of the literature from 1970 to 1991. Journal of Research in Science Teaching, 32(4), 387-398.

Yaman, S. ve Dede, Y. (2007). Öğrencilerin fen ve teknoloji ve matematik dersine yönelik motivasyon düzeylerinin bazı değişkenler açısından incelenmesi. Kuram ve Uygulamada Ĕ̆itim Yönetimi, 52, 625-638.

\section{Kaynakça Bilgisi / Citation Information}

Özcan, M. (2021). Ortaokul öğrencilerinin araştırma-sorgulamaya yönelik tutumları. OPUS-Uluslararası Toplum Araştırmaları Dergisi, 18(44), 8261-8279. DOI: 10.26466/opus. 892503. 